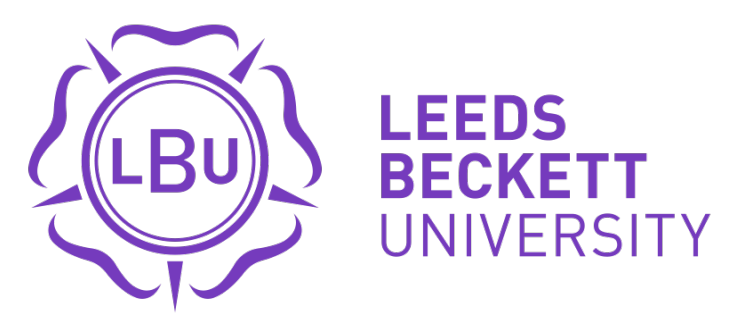

Citation:

Clegg, S (2016) The necessity and possibility of powerful 'regional' knowledge: curriculum change and renewal. Teaching in Higher Education, 21 (4). 457 - 470. ISSN 1356-2517 DOI: https://doi.org/10.1080/13562517.2016.1157064

Link to Leeds Beckett Repository record:

https://eprints.leedsbeckett.ac.uk/id/eprint/2593/

Document Version:

Article (Accepted Version)

his is an Accepted Manuscript of an article published by Taylor \& Francis in Teaching in Higher Education on 9 March 2016, available online: http://www.tandfonline.com/10.1080/13562517.2016.1157064

The aim of the Leeds Beckett Repository is to provide open access to our research, as required by funder policies and permitted by publishers and copyright law.

The Leeds Beckett repository holds a wide range of publications, each of which has been checked for copyright and the relevant embargo period has been applied by the Research Services team.

We operate on a standard take-down policy. If you are the author or publisher of an output and you would like it removed from the repository, please contact us and we will investigate on a case-by-case basis.

Each thesis in the repository has been cleared where necessary by the author for third party copyright. If you would like a thesis to be removed from the repository or believe there is an issue with copyright, please contact us on openaccess@leedsbeckett.ac.uk and we will investigate on a case-by-case basis. 


\section{The necessity and possibility of powerful 'regional' knowledge: curriculum change and renewal}

\section{Sue Clegg}

\section{Introduction}

There has been a significant increase in the number of papers and books theorising the importance of curriculum in higher education with a range of theoretical resources being drawn on, singly and in combination, including: Bernsteinian theory (Bernstein 2000), critical realism (Bhaskar 1978), and Legitimation Code Theory (Maton 2014). This marks a shift away from thinking about generic teaching and learning and is an important re-orientation towards considering knowledge questions which had been largely neglected in social constructionist accounts of student learning. The paper will advance a number of theoretical arguments and also reflects back on earlier curricula innovations since patterns of change are often only evident in retrospect. The paper revisits the debates about regionalisation and powerful knowledge which have derived from the classic Bernsteinian perspective which conceptualises regionalisation as the recontextualization of traditional disciplines for professional and vocational fields of study. Following Young and Muller (2014) I argue that traditional regional knowledge in the professions eg medicine and engineering can legitimately be seen as constituting powerful knowledge. There are, however, pressing regional knowledge issues in relation to newer professional and vocational areas especially when these are considered in the context of the global 'south' and not just the 'north'. The analysis of these issues needs to take into account the institutional diversity found in mass higher education systems as well as broader geo-political inequalities. The argument for 'necessity' in the title, therefore, signals the importance of curriculum developments if these challenges are to be met. The paper will also develop a set of arguments about regionalisation, distinct from the Bernsteinian ones, which have both geo-political and social movement dimensions. These involve a broader conceptualisation of regionalisation as looking outwards from the academy to knowledge claims and challenges which originate outside the academy and the traditional professions. These arguments are especially significant in a global context since they speak to knowledge making practices and actors often excluded from debates about knowledge, disciplines, and indeed regions in the Bernsteinian sense. I will argue that they have geo-political and social justice implications and that the issue of whether curriculum developments which draw on these practices constitute powerful knowledge is an important one.

The question of curriculum relates closely to social justice issues because while there has been a major increase in participation rates globally with gross enrolment rates globally standing at $26 \%$ in 2006 this masks huge disparities; low income countries had 7\% enrolments compared to $67 \%$ for high income countries with Sub Saharan Africa at $6 \%$ and the US at 70\% (Altbach, Reisberg and Rumbley 2009). ${ }^{\mathrm{i}}$ The UNESCO authors put this most starkly when they argue:

The 'logic' of massification is inevitable and includes greater social mobility for a growing segment of the population, new patterns of funding of higher education, increasingly diversified higher education systems in most countries, and an overall lowering of academic standards (Altbach, Reisberg and Rumbley 2009, i)

The curriculum challenge becomes whether, once we move beyond an education that caters only for an elite, the controversial claim made above about the inevitability of the 'lowering of academic standards' pertains. In other words can there be a broader set of regional 
knowledges, both the Bersteinian and in the broader sense of knowledge generated outside the academy, that nonetheless have the characteristics of powerful knowledge? Access is not just a question of entering higher education it also becomes an issue about what is being accessed in institutionally diverse higher education systems. Epistemic access is increasingly recognised as being as significant a challenge as social access. We need to consider the sort of knowledge, engagement, and opportunities that are open to newer actors, both educators and students, especially if debates (as they should) encompass the global 'south' and are not confined to the global 'north'.

Historically, elite systems were in many ways uncomplicated in that knowledge prepared mostly white middle and upper class men for their roles in the professions and as leaders and rulers. In the twentieth century science came into prominence and with that an increased stress on the importance of research and these developments went hand in hand with a continued recognition of the importance of a liberal arts curriculum in the education of an elite. This is a pattern that we can still see in many elite institutions today (Tight 2009). The cultivation of the mind and abstract critical thought is recognised as giving access to what Wheelahan (2010) and Young (2008) among others have described as 'powerful knowledge'. The idea of powerful knowledge is important because it involves the claim that it is more than just the knowledge of the powerful (although of course it is also that). Powerful knowledge is knowledge which gives access to better and more reliable explanations of the world and abstract ways of thinking: 'Powerful knowledge is powerful because of the access it provides to the natural and social worlds and to society's conversation about what it should be like' (Wheelahan 2010, 10). The question, therefore, is if and how in greatly expanded and institutionally diverse higher educational systems we can design curricula that give access to powerful knowledge while recognising the complexity of professional and other forms of applied education (Muller 2009). These varied curricula do not necessarily take on the conventional forms found in elite settings so the question of powerful knowledge involves more than just a restatement of the value of traditional disciplines, although epistemic access to these also remains an important issue.

In order to address some of these questions the paper is structured in four parts along with some tentative conclusions. The first section considers the analytical framework and particularly the concepts of regionalisation and powerful knowledge drawing on the work of Basil Bernstein (2000). The second section considers regionalisation in relation to professional curricula and makes the case that it is possible for regional knowledge to be powerful and that there are historical precedents for affirming this. The third section looks at newer forms of regional knowledge in terms of newer professions and global unevenness and contexts (Naidoo 2014). It explores how and under what circumstances genuinely critical and powerful regional knowledge can be developed in ways that meet the demand for both conceptual and contextual coherence (Muller 2009). The fourth section takes up the argument about social movements. It consciously expands the concept regionalisation, because while most forms of regionalisation have been understood as responding to the externalities of the market and the professions (Bernstein 2000) there are other sorts of knowledge challenges that are generated outside the academy but with which the academy has engaged including those developed by social and political movements. Examples of this are more easily found in relation to social sciences and humanities and there is a more open question of, if and how, ecological and environmental movements, for example, might fit under this description when the parent disciplines of the social movement originate in scientific discourse. These newer forms of regionalisation are controversial and have been critiqued by some key curriculum theorists as being predominately a form of 'voice' epistemology and as resting on social constructivist arguments with negative implications for the development of powerful 
knowledge in both the traditional singulars and regions (Moore, Muller 1999, Young 2008). The argument for the possibility and necessity of powerful regional knowledge in this sense, therefore, needs to be carefully made. The final concluding section explores what the implications are for curriculum development and also for research because we need more empirical studies to properly resolve some of the questions I raise. In particular, it is important to establish whether the disciplinary bases of some regions render them more or less susceptible to knowledge claims from outside the academy. Many of my arguments are inevitably speculative - but that is not necessarily a bad thing if they invite debate and inspire us to do the necessary theoretical and empirical work that questions of curriculum entail.

\section{Powerful Knowledge, Singulars, and Regionalisation}

Traditional disciplinary knowledge, what Bernstein describes as singulars, appears to encapsulate the virtues of powerful knowledge and indeed the two concepts are largely coterminous. The idea of powerful knowledge was developed by Young (2008), among others, because they wanted to capture the characteristics of knowledge that went beyond the insight that all knowledge is socially constructed, which of course it is, and to focus on the distinctiveness of knowledge practices and claims. Wheelahan (2010) has developed the argument for powerful knowledge by linking it to critical realism which makes the case for the importance of both the social epistemic dimensions of knowledge making and its ontological dimensions. All knowledge making is necessarily social, to quote Andrew Sayer:

it is imperative to consider the production of knowledge as a social activity. To develop knowledge we need raw materials and tools on which we can work. These are linguistic, conceptual and cultural as well material. In trying to understand the world, we use existing knowledge and skills drawn from whatever cultural resources are available, to work upon other 'raw' materials - knowledge in the form of data, pre-existing argument, information or whatever. (Sayer 1992, 16)

Critical realists insist, however, that the social transitive dimension of knowledge making is about making sense of an intransitive world which exists independently of us (while acknowledging that the objects of social science are only relatively enduring). It is this 'aboutness' that allows us to make always fallible knowledge claims. Wheelahan (2010) has mobilised these critical realist ontological claims to strengthen the arguments that can be advanced about powerful knowledge and the importance of knowledge in relation to disciplines. Disciplinary claims and practices can be judged against their ability to produce non-arbitrary explanations of the mechanisms at work in ways which can account for the phenomenal world of our experiences. In accessing disciplinary learning students are being inducted into ways of knowing about the world and its relations as a basis for making, always fallible judgements, about the validity of these claims. Critical realism, therefore, provides the basis for recognising the inherent sociality of knowledge making without collapsing into judgemental relativism. It also provides a break with the claim made by some constructivists who suggest that powerful knowledge is merely the knowledge of the powerful.

The work of Wheelahan extends Bernstein's (2000) account of disciplinary knowledge which drew on different intellectual roots. Bernstein drew on Durkheim's (1995) distinction between the sacred and the profane, and applied it to an understanding of the structures of knowledge and academic disciplines and the boundary between theoretical (sacred) and everyday (profane) knowledge. Disciplinary knowledge is special by virtue of the way it develops. Disciplinary knowledge, however, is not the same as curriculum knowledge and he explored what he called the 'recontextualization' rules whereby the knowledge in the disciplines is 
recontextualised into curriculum and pedagogy using ideas of 'classification' and 'framing'. Classification refers to the relations between categories and disciplines can be strongly or weakly classified. Framing refers to the control over 'the selection, sequencing, pacing and criteria of the knowledge to be acquired' (Bernstein 2000, 99) and this can be strong or weak. Bernstein offers a rich resource for understanding disciplinary structures and their pedagogisation. His analysis allows us to distinguish between vertical knowledge structures in science disciplines and horizontal structures in the humanities (which do not allow for cumulative evidential warrant in the same way as in science). Crucially for the argument of this paper Bernstein distinguished between disciplinary singulars with 'their own intellectual field of texts, practices, rules of entry, examinations, license to practice, distribution of rewards and punishments' (Bernstein 2000, 52) which are characterised by strong boundaries and hierarchies (both strongly classified and framed) and regions which 'are constructed by recontextualising singulars into larger units which operate and in the field of external practice.' (Bernstein 2000, 52). There is a historical dimension to this distinction. The elaboration of singulars in the nineteenth century was closely linked to the development and administration of empire. Thus even in the case of singulars there is a degree of outward looking towards the profane.

despite these external linkages singulars are like a coin with two faces, so that only one face can be seen at any one time. The sacred face sets them apart, legitimates their otherness and creates dedicated identities with no other reference than to their calling. The profane face indicates their external linkages and internal power struggles. (Bernstein 2000, 54)

So while singulars are introjected the contrast between singulars and regions is not as stable and dichotomised as perhaps might be suggested. Wheelahan (2010) supports this interpretation and she argues that the development of singulars 'was directly related to the development of regions' (Wheelahan 2010, 26).

The final distinction that Bernstein made, which is elaborated by Wheelahan, is that of a newer performance mode namely the generic. This mode, with its origins in human capital theory, evolved an abstract notion of 'trainability' devoid of knowledge content and where, as Wheelahan (2010) argues, the relationship between knower (inner) and known (the world) is reversed so that 'the outer is now the principle of selection of the inner' (Wheelahan 2010, 28 ). The identification of the generic is central to her analysis of vocationalisation and the ways instrumentalism in the official recontextualisation field (ORF) came together with social constructivism in the pedagaogic recontextualisation field (PRF) to produce a denuded curriculum. This mode denies students' access to powerful knowledge as it does not embody the attributes of powerful knowledge discussed above. Regional knowledge is also problematic and it has been argued that newer professional and vocational education is susceptible to the process of 'vocationalisation'(Muller 2009). These developments are particularly troubling as they are more common in less prestigious institutions accessed by the least privileged students. Before going on to consider the problem of newer professions and contexts, however, I want to argue that powerful regional knowledge is possible and that there are clear historical precedents which illustrate the case.

\section{Powerful regional knowledge}

There are examples of powerful regional knowledge within the foundational bases of the modern academy. Medical science and medical education have a long history with a developed research and knowledge base beyond that of their contributory singulars. Medicine's prestigious social position also affords it considerable autonomy in the pedagogic 
recontextualisation field. Engineering is another case with engineering science and research taking distinctive form from its singulars. Smit (2012) has shown, for example, that the way thermodynamics is understood and recontextualised into the engineering curriculum is different to ways it is understood in specialist physics courses. She shows that the engineering curriculum draws its knowledge not only from its contributory singulars but also directly from the field of practice itself. It can legitimately be argued, therefore, that both engineering and medicine have 'a consecrated and canonised body of specialised professional knowledge that represents the stable repertoire gleaned from earlier research' (Young and Muller 2014,14).

Knowledge and curriculum in these areas are distinctive and challenging and we have empirical studies which can demonstrate the ways in which they differ from singulars. One such study uses Maton's (2014) extension of Bernsteinian categories to analyze the Mechatronics curriculum in engineering. Using the category of semantic gravity which indicates the degree to which knowledge is tied to its context and where 'abstraction' involves weak semantic gravity and 'reproductive description' the authors of the study map the movement of problem solving moments - the 'semantic wave' - across the curriculum:

What the interviews appear to indicate is that integrating and applying knowledge in Mechatronics engineering is essentially the ability to draw on knowledge from different disciplinary/regional areas, and build the knowledge cumulatively by moving (in wave form) up and down a context-dependency scale of semantic gravity. The separable contextually visible disciplinary regions are mechanical, electrical and programming, and they generally flow in this order. Over time, however, they merge into a 'system'. (Wolff and Luckett 2013, 88)

This form of recontextualised regional knowledge has the characteristics of powerful knowledge in both the critical realist sense and the more strongly Bernsteinian account offered by Young (2008).

Young and Muller (2014) have extended our understanding of this sort of professional knowledge. Following Bernstein (2000) they argue that there are two kinds of theoretical knowledge depending on whether they elaborate hierarchically, as in most sciences, or horizontally as in the humanities. They argue, however, that in both the conceptual cores advance hierarchically - although in the humanities that advance takes place within different stems as new paradigms or frameworks are advanced. Professional knowledge is specialised to develop conceptually and is specialised to a contextual purpose. Muller (2009) argues that the issue is not whether regionalisation is good or bad as such but whether the form of regionalisation can sustain a curriculum that is both conceptually and contextually coherent. Most medical curricula are strongly classified and framed, as indeed are engineering curricula. In the case of the latter Case (2014) suggests caution in the introduction of a problem based curriculum. She argues an unintended consequence might be that this makes epistemic access for the least privileged students more difficult rather than facilitating it, a caution which also applies in medical education. These are important debates but it is clear that when considered from both a critical realist perspective and from a Bernsteinian one there are well established professional curricula which meet the definition of powerful knowledge.

\section{Newer regions and curriculum developments}

As already suggested, however, there are particular challenges when considering newer regions and curriculum development. The first relates to specialisation to the contextual purpose when the context in question is understood as being beyond the global 'north'. The second relates to newer professions, often lacking in the professional kudos to define their 
knowledge base. This is especially problematic in cases where the recontextualising principles for earlier years of training have been developed in different educational settings that may not provide an adequate basis for conceptual knowledge building at more advanced levels (Shay 2013), and where the ORF is strong in relation to relatively weaker professional control over the PRF (Scott et al 2009). The third major challenge is the one Wheelahan (2010) identifies of generic vocational courses and the reframing of newer professional courses on generic principles in ways that undermine the potential for the development of powerful regional knowledge.

The first argument relates to contextual purpose and involves a recognition that the context of enactment for professional education is not globally static and that external conditions vary between countries. Most traditional professional courses were developed in the global north with professional curriculum development in health for example being mapped onto the division of labour in advanced health systems. Heath care systems, however, vary widely in terms of resources, organisation and the patterns of health and disease. One example is how curricula are being rethought in relation to the contextual purpose of primary health care in the South African context. The external context and the ORF, and the internal requirement to ensure social and epistemic access for students previously systematically disadvantaged under apartheid, is providing the impetus for major reviews of the curriculum to reframe them in terms of social responsiveness and primary health care approaches (Hartman et al 2012). Amosun et al (2012) and Hartmann et al (2012) describe the process of transforming of undergraduate programmes in audiology, occupational therapy, physiotherapy and speech therapy. The aim has been to develop and implement strategies in 'curriculum transformation' (Amosun et al 2012, 37). The authors have been documenting and researching the process but have not published work which looks at the curriculum terms in terms of access to powerful knowledge. The underlying point, however, is the more general one that regional in a geopolitical sense matters for the development of contextual coherence. Furthermore, contextual coherence is central to regionalisation in the Bernsteinian sense and the degree of verticality required for sustaining a conceptual coherence which can support epistemic as well as social access. There is no relation of necessity. 'Western' medical curricula were developed in particular (changing) contexts yet were able to develop a clear knowledge base and conceptual purpose with epistemic warrant. It seems highly likely that different underlying mechanisms are at work in different health systems at the social and political level even if not at a fundamental biological level. The challenge of attaining conceptual and contextual coherence in developing new curricula also relates to the specific power dynamics between the local ORF and PRF. Basing their new curriculum on the specific 'biopsychosocial' dynamics (Hartman et al 2012) of their situation is, therefore, to recognise the interplay of systems in open not closed (ie experimentally controllable) social settings.

The second challenge is to consider the recontextualisation rules in relation to singulars and the contextual purpose that forms the curriculum basis for newer professions. As Scott et al (2009) in their study of Professional Doctoral Education point out some newer professions (in their example education) are more susceptible to pressure for the ORF than established ones such as engineering. Nursing as a newer profession is interesting because nursing research (as distinct from medical) was established at around the same time as nursing degrees began to be established. Nursing research began to be established in the 1960s (Gortner 2000) as a form of 'canonised' research in the field distinct from its singulars. The first nursing degree in the UK was Edinburgh University in 1956 while the first Doctor of Nursing Science programmes developed in the USA in the 1960s. The recontextualised singulars of developing nursing degree programmes in the 70s and 80s in the UK varied widely with some courses having a heavy biomedical component and others more psychosocial, but in both considerable research 
and curriculum effort went into developing nursing knowledge as distinctive. This history suggests that knowledge was a central component in the creation of the region and was understood by practitioners at the time to be so.

It is also important to consider where education is taking place and how curricula are differentiated between different levels of qualification. Greater attention is now being paid to curriculum differentiation and different occupational fields and knowledge (Muller 2009). Shay (2013), for example, drawing on Maton (2014), has mapped curriculum routes in relation to their degrees of semantic gravity (the extent to which knowledge is tied to context) and semantic density (which maps the internal relations of the knowledge practices in terms of the degree of condensation of meaning within symbols). Her work focuses on problematic issues of progression and articulation between practical, generic, professional, and academic curricula. This has troubled nursing for example where historically some qualifications and settings offered a highly practical curriculum with little access to later professional routes and even less access to the (now compulsory) academic degree routes in English higher education. This practical route has now in effect been de-coupled from full nurse status and serves the development of a separate, low paid, and low status workforce. So while regionalisation can provide access to powerful knowledge for newer professions in some contexts and settings there is nothing automatic and it remains a site of social contestation and struggle.

The final category of the generic has been forensically dissected by Wheelahan (2010) and I will not repeat this here. Her subtle analysis shows how under pressure in the ORF and under the influence of social-constructivism in the PRF knowledge relations can be lost from view with negative consequences for those least privileged in higher education. Moreover, these generic aspects are becoming more common across the curriculum in less prestigious sites and the rhetoric of employability and pressure from the ORF is encouraging curriculum designers to increase the amount of attention given to generic components (Clegg 2014) to the potential detriment of access to powerful knowledge.

\section{Regionalisation and knowledge outside the academy}

One of the pitfalls of the emphasis on the sacred and the university is the downplaying of knowledge which originates outside the academy and particularly from within social movements. Zipin, Fataar and Brennan (2015) for example have challenges the social justice credentials of Bernsteinian approaches in part based on a critique of the distinction between the scared and the profane. Many advances in knowledge have been made by intellectuals working outside the academy (Collini 2006, Evans 2004). Moreover, in the nineteenth century the development of some disciplinary singulars (sociology, politics, economics) were in part a reaction to the political economy of Marx and other socialist writings. These ideas were subsequently recovered, including the anti-colonial writing of figures such as C. L. R. James, and had a major impact on social science curricula from the late 1960s. Pointing to the social origins and purposes of ideas does not close down the arguments about the validity of specialised knowledge claims. Bernstein is quite clear that:

The evolution of a range of singulars, specialised knowledge structures of the division of discursive labour, is very much a phenomenon of the last century. The development of English was linked to the development of nationalism and Britain's international position at the end of the nineteen century.' (Bernstein 2000, 54)

A reading of some of the products of the colonial imagination in the form of academic anthropology now makes us blush as indeed do accounts of women's abnormal anatomy and intellectual functioning found in nineteenth century medical textbooks. My argument is not 
that these accounts were wrong because they were produced by white men (although they largely were) but because we have more powerful (although fallible) accounts to draw on and that some of these critiques were developed by activists outside the academy and were resisted inside it. The women's health movement, for example, was crucial for improvements to childbirth. It mobilised knowledge claims derived from the biosciences and social sciences to challenge medical procedures and education (Clegg 2005). There are, therefore, fruitful ways of thinking about regionalisation that recognise the importance of texts and ideas originating outside the academy. This is significant when we look globally towards renewing and reconfiguring curricula in ways which do not merely reproduce the common citation practices (particularly in the social sciences and humanities) of referring mostly to 'northern' authors. Before elaborating my argument further, however, I will consider some arguments about 'voice' because there is a hostility towards voice epistemologies (which I largely share) that has obscured serious consideration of ideas from social movements

The negative tone of approaches to social movements among some curriculum writers can be traced to Bernstein ${ }^{\mathrm{ii}}$ and his analysis of perspective identities:

Perspective identities are often launched by social movements, for example gender, race and region. They are in their takeoff stage evangelical, and ..have strong schismatic tendencies. (Bernstein 2000, 76)

This is a perfectly reasonable sociological observation; however his antagonism is hardly concealed as he goes on to describe how junior members of such groups produce more radical agendas which he illustrates using the 'caricature' (his word) of height:

New membership criteria in the new narrative sets membership at three and a half inches below average height. Most of my group are excluded and now seen as part of otherness. We have the first schism and a new shrinking of moral imagination. (Bernstein 2000, 77)

He claims that members of these new movements argue that valid research can only be carried out by a member of the right social category. There have been arguments within social movements about voice, commonly known as 'voice' epistemologies, and deriving from a Hegelian reading of Marxism by Lukács (1971) and built on by Hartsock (1998) and Harding and Hintikka (1983). But the arguments have been considerably more nuanced than Bernstein appears to have recognised. Lukács analysed commodity fetishism which involves a process of reification whereby social process are seen as natural facts. Exploitation is systematically masked through these operations and this in turn allows the powerful to systematically misrecognise the source of their power and wealth, the parallel in feminism is the naturalisation of male power and privilege. There is a careful argument about why certain social categories of persons (the working class or women) are more likely under certain circumstance and because of their social positioning to be able see through the doxa and produce better knowledge claims. It was after all the women's movement, in very particular historical circumstances, that allowed some women to claim to produce better accounts of their condition. This is not to deny that there are some versions of voice discourses that reduce knowing to an essentialised identity and versions of intersectionality theory that come rather too close to Bernstein's caricature for comfort - and I have been critical of both (Clegg 2011, 2012). Maton (2014) offers a far more nuanced account of the 'knower' problem basing his analysis on a particular moment in British cultural studies he shows how in that particular setting a proliferation of knowers did emerge. His concern is with elaborating and distinguishing epistemic and social relations and interestingly, as I will show later, some curriculum theorists (Luckett 2015) are drawing on this work for purposes of curriculum reform in the South African context that draws on and uses texts produced outside the academy. 
The detour to arguments about voice is necessary and are indeed foundational to arguments about bringing 'knowledge back in'. Voice arguments have been prominent in the sociology of education as Moore and Muller (1999) argue in their influential paper The Discourse of 'Voice' and the Problem of Knowledge and Identity in the Sociology of Education. They claim that identity politics and a post-structuralist celebration of diversity undermined considerations of epistemic warrant and knowledge. They are very clear, however, that the issues that were being raised were real ones:

Disparities of access and representation in education were (and are) rightly seen as issues that need addressing and remedying, and in this sense constitute a genuine politics. It is important to stress, here, that the issues are real issues and the work done on their behalf is real work. But the question is: is the politics best pursued in this way? (Moore, Muller 1999, 191)

Their argument that the politics of voice is not the best way and I agree. They demonstrate that there are no necessary internal relations between theories of knowledge, forms of education and social relations and that seeing them as such undermines knowledge based forms of education that are of fundamental importance for social justice. I would go further and, following Callinicos' (1989) argument, suggest that post-structuralism (or postmodernism) arose out of political defeats which were the result of the success of the neoliberal strategy for the rebalancing of power from the Thatcher and Reagan era onwards. The influence of post-structuralist ideas in the sociology of education is an important topic, but ideas from social movements were not reducible to voice arguments even at the highpoint of voice epistemologies. Rather curriculum challenges emerged as newer social groups entered the academy and developed new knowledge claims (not as a matter of internal necessity as critiqued by Moore and Muller 1999) but as a sociological reality in the formation of new social movements.

There is now a huge social movement literature. Here, however, I want to make some particular claims. Feminism was never a unified project (Segal 1999), social movements rarely are. But feminists asked new questions about their social position, created a new language for naming wrongs (sexual harassment for example), and were able to point to the almost complete absence of women in the curriculum of the 1960s. In the Sociology of Modern Britain, a double Sociology paper at London University in the late 60s, for example, women received barely a mention beyond Women's Two Roles by Alva Myrdal and Viola Klein (1956). The history curriculum was similarly restricted - women hardly featured. There was an outpouring of new research and writing from the 1970s onwards from both inside and outside the academy. This writing was diverse in its epistemological and methodological claims and in the topics it addressed. New areas in need of theorisation were opened up and as some of the new entrants to higher education went onto obtain positions in the then expanding newer Universities and Polytechnics new curricula began to be developed. This was not restricted to women's studies but manifested itself across the humanities and social sciences and to a lesser extent in the sciences (although many of the struggles there were confined to social access not knowledge questions). This was not confined to women or solely to ideas from the women's movement. Ideas from Civil Rights, from Marxism and the New Left, from Black Power, and anticolonial writing represented serious challenges to the curriculum. These were (always fallible) knowledge challenges and pointed in some cases to serious flaws and absences in existing scholarship. Of course not all the challenges to curriculum and research were generated in this way. Cumulative immanent critique and scholarship in the singulars also contributed. It is important to look at historical moments 
when there are qualitative shifts in momentum, however, if an adequate account of the development of higher education is to be offered.

As in the case of newer professions, rehearsed in the previous section, these arguments about regionalisation can be thought of in conjunction with the idea of regional in a geo-political sense since what is outside the academy is not uniform. Local context matters and this is not in and of itself a threat to the argument for the importance of a reorientation towards knowledge questions. Curriculum development needs to be alert to questions that have been thrown up by, for example, Southern Theory (Connell, 2007), African-Centred Knowledge (Cooper, Morrell 2014), and the legitimacy struggles highlighted by the Rhodes Must Fall Movement (2015). Rhodes Must Fall referred to a statue of Cecil Rhodes that was (then) in a prominent position on the University of Cape Town campus. The successful campaign to remove the statue, however, raised broader questions including curriculum matters and, as argued by Soudien (2015), involved ontological, epistemological, and axiological questions. When thinking about curriculum implications great, however, care has to be exercised. The much cited Southern Theory by Connell (2007) for example does not espouse a relativist epistemology and its analysis of citation patterns makes substantive empirical claims. Recent essays on African Centered Knowledge (Cooper and Morrell 2014) includes arguments based on strong realist claims for a rewriting of previously bad scholarship as well as post-modern ones. My argument is that we should not and cannot ignore demands for curriculum reform from new actors in higher education. Luckett (2015, and in this volume) has approached curriculum renewal with an acute sense of the continued injustices inherited from apartheid and in the light of recent student protests. Her work gives the clearest example of how ideas generated from outside the academy can be analyzed using tools derived from Legitimation Code Theory (Maton 2014). As part of efforts to reform the curriculum she analyses strands within African epistemologies (Luckett 2015) to distinguish born, social, cultivated, and trained gazes in knower codes in the humanities. The resultant curriculum is one that is dealing with knowledge questions but in a way that is relevant to the particular African context and the experiences of students.

It is telling that my examples have come largely from the humanities and social sciences. There is more work to do looking at the relationship between the more strongly codified and classified singulars that form the basis of other new regions. The relationship between curriculum development in newer environmental sciences for example and the social movements that have undoubtedly driven their popularity, if not necessarily their knowledge base, requires exploration. It may be that some singulars and regions are more firmly rooted in the academy and less susceptible to influence from outside than others but this is a matter for exploration rather than to be dismissed out of hand. Moreover, knowledge questions should also properly be thought about in relation to recognition and there are good critical realist arguments for doing so (Sayer 2005). A rejection of voice epistemology does not entail the erasure of the particular voices of students and affirming and developing a pedagogic identity is essential to learning (Soudien 2015). So while the questions of new students and new demands might be inflected differently across disciplines the challenge of epistemic access requires considerable curriculum thought.

\section{Conclusions}

Although I have dealt with a number of arguments in the separate Sections and interspersed these with arguments about the significance of the local context within a global set of relations I am aware that there is much more that needs to be developed. The processes involved in regionalisation, in both the Bernsteinian and in the broader sense outlined above 
as involving knowledge generated outside the academy, require greater empirical elaboration and their analysis needs to be sensitive to geo-political context. Some of this empirical data will come from outside the sociology of education. What we need to do inside higher education is to keep these arguments to the forefront in practical curriculum work. Wheelahan rightly asserts that:

Bringing the social and epistemic together provides the basis for critiquing curriculum so that knowledge is judged by the extent to which it provides access to its objects, as well as the extent to which curriculum provides students with access to the structure of knowledge and systems of meaning (Wheelahan 2010, 47)

What curriculum renewal should not do is offer some students a knowledge-weak generic curriculum, but equally we should not assume that all is well with the singulars and in traditional regions. Social movements and students still have the capacity to challenge the academy including for example the problematic economics curriculum that some students argued left them lacking the tools to make sense of the crash (Post Crash Economics Society 2015).

In concluding I am aware that I have differentiated institutions very loosely referring to more and less privileged sites whereas the diversity in the system is enormous. One cannot simply read curriculum from institutional setting. Work by Mclean, Ashwin and Abbas (2013) on sociology courses, where pressures towards regionalisation are high, found that curriculum and pedagogy could not be read off from the ranking of universities. Staff in less prestigious sites had maintained a curriculum that challenged their students in the same sorts of ways as in more elite spaces and the differences they found were not simply reducible to institutional type. If we are to make epistemic access a reality, we clearly need more studies which look at the relationships between newer curricula, powerful knowledge, and what students at both more and less prestigious institutions are being offered. We also need to keep disciplinary singulars in our sights. Based on the work we already have, however, I think we can make an argument that rigorous powerful regional knowledge, in both the senses I have used it, is possible and alongside Wheelahan (2010) assert that it is necessary.

\section{References}

Altbach, P. G. Reisberg, L. Rumbley L. E. 2009. Trends in Global Higher Education:

Tracking an Academic Revolution. Accessed 3 April 2015

http://www.uis.unesco.org/Library/Documents/trends-global-higher-education-2009-worldconference-en.pdf

Amosun, S. I. Hartman, N. Janse van Rensburg, V. Duncan, E. M. Badenhorst, E. 2012.

"Processes in widening access to undergraduate allied health sciences education in South

Africa." AJHPE 4 (1): 34-39.

Bernstein, B. 2000. Pedagogy, Symbolic Control and Identity, Theory, Research, Critique. Oxford:

Rowan \& Littlefield.

Bhaskar, R. 1978. A Realist Theory of Science. Brighton: Harvester Press.

Callinicos, A. 1989. Against postmodernism: A Marxist Critique. Cambridge: Polity.

Case, J. 2014. Probelmatising Curriculum: Contemporary Debates in Engineering Education

in Young, M. Muller, J. eds. 2014. Knowledge, Expertise and the Professions. 143-156

London: Routledge.

Clegg, S. 2011. "Cultural capital and agency: connecting critique and curriculum in higher education." British Journal of Sociology of Education 32 (1): 93-108. 
Clegg, S. 2012. A morphogenetic analysis of intersectionality. Invited Keynote Kritische Soziologie Meets Critical Realism. Friedrich-Schiller-University Jena $1^{\text {st }}-3^{\text {rd }}$ Feb.

Clegg, S. 2014. Different Times: temporality, curriculum and powerful knowledge In P. Gibbs, O. Ylijoki, C. Guzmán-Valenzuela, R. Barnett (Eds) Universities in the Flux of Time 108-120 London, Routledge.

Clegg, S. 2005. Evidence-based practice in educational research: a critical realist critique of systematic review, Sociology of Education 26 (3): 415-428.

Collini, S. 2006. Absent Minds intellectual in Britain. Oxford: Oxford University Press.

Connell, R. 2007. Southern Theory. Cambridge: Polity.

Cooper, B. Morrell, R. eds. 2014. African-Centred Knowledge: Crossing fields and worlds.

Suffolk: James Currey.

Durkheim, E. 1995. first edition 1912. Elementary Forms of Religious Life. New York: The Free Press.

Evans, M. 2004. Killing thinking: the death of the universities. Continuum, London, UK.

Gortner, S. R. 2000. "Knowledge Development in Nursing: our Historical Roots and Future Opportunities" Nursing Outlook 48 (2): 60-67.

Harding, S. Hintikka, M. B. 1983. Discovering Reality: Feminist Perspectives on

Epistemology, Metaphysics, Methodology, and Philosophy of Science. Boston: D. Reidel Pub. Co.

Hartman, N. Kathard, H, Perez, G. Ried, S, Irlam, J. Gunston, G. Janse van Rensburg, V.

Burch, V. Duncan, M. Hellenburg, D. van Rooyen, I. Smouse, M. Sikakana, C. Badenhorst, E. Ige, B. 2012. "Health Sciences undergraduate education at the University of Cape Town: a story of transformation." Forum 102 (6): 477-480.

Hartsock, Nancy C.M. 1998. The Feminist Standpoint Revisited, and Other Essays. Boulder: Westview Press.

Luckett, K. 2015. Gazes from the Post-colony: an analysis of African epistemologies using Legitimation Code Theory Paper presented at the LCT Conference, Cape town 17 - 19 June 2015.

Lukács, G. 1971. History and Class Consciousness: Studies in Marxist Dialectic. Brecon: The Merlin Press.

Maton, K. 2014. Knowledge and Knowers: Towards a realist sociology of education.

Abingdon: Routledge.

McLean, M. Abbas, A. Ashwin, P. 2013. "The use and value of Bernstein's work in studying (in)equalities in undergraduate social science education." British Journal of Sociology of Education 34 (2): 262-280.

Moore, R. Muller, R. 1999 "The Discourse of 'Voice' and the Problem of Knowledge and Identity in the Sociology of Education." British Journal of Sociology of Education 20(2):189206.

Muller, J. 2009. "Forms of knowledge and curriculum coherence" Journal of Education and Work 22 (3):205-226.

Myrdal, A. Klein, V 1956. Women's Two Roles. London: Routledge and Kegan Paul.

Post Crash Economics Society 2015. Accessed 20 ${ }^{\text {th }}$ August 2015 http://www.post-

crasheconomics.com/

Naidoo, R. 2014. Transnational Higher Education: Global Wellbeing or Imperialism?

Keynote Presentation. United Kingdom Forum for International Education UCL Institute of Education 24 October

Rhodes Must Fall Accessed 10 ${ }^{\text {th }}$ September 2015 http://rhodesmustfall.co.za/

Sayer, A. 1992. Method in Social Science. London: Routledge.

Sayer, A. 2005. The Moral Significance of Class. Cambridge: Cambridge University Press. 
Scott D. Brown A. Lunt I. Thorne L. 2009. Specialised knowledge in UK professions: relations between the state, the university and the workplace. In D. Boud A. Lee (eds) Changing Practices of Doctoral Education. London: Routledge.143-156.

Segal, L. 1999. Why Feminism? Cambridge: Cambridge University Press.

Shay, S. 2013. "Conceptualizing curriculum differentiation in higher education: a sociology of knowledge point of view" British Journal of Sociology of Education 34 (4): 563-582.

Smit, R. 2012. "Engineering Science and Pure Science do Disciplinary Differences Matter in Engineering Science?" Paper presented at Annual Conference of Austrasian Association for Engineering Education Melbourne 3-5 December.

Soudien, C. 2015. "Of False-Starts, Blind Spots, Cul-de-Sacs and Legitimacy Struggles: The Curriculum Debates in South African Higher Education. Panel Discussion What does "decolonising the curriculum" mean for Education Studies? University of Cape Town $21^{\text {st }}$ August 2015.

Tight, M. 2009. The Development of Higher Education in the United Kingdom since 1945. Maidenhead: SRHE \& OUP.

Wheelahan, L. 2010. Why Knowledge Matters in Curriculum: A social realist argument. Abingdon: Routledge.

Wolff, K. Luckett, K. 2013. "Integrating multidisciplinary engineering knowledge" Teaching in Higher Education 18(1): 78-92.

Young M. 2008. Bringing Knowledge Back In: From social constructivism to social realism in the sociology of education. London: Routledge.

Young, M. Muller, J. eds. 2014. Knowledge, Expertise and the Professions. London:

Routledge.

Zipin, L. Fataar, A. Brennan, M 2015. Can Social Realism do

Social Justice? Debating the Warrants for Curriculum Knowledge Selection. Education as Change 19 (2): 9-36

\footnotetext{
' Although these data are now 10 years old the most recent UNESCO raw data does not offer a breakdown by region only by country. The broader analysis, however, relating to unevenness still holds.
}

ii This insensitivity is even more strange as more sophisticated work was available at the time, including the case of British Cultural Studies elaborated in Maton 2014, which Bernstein cites in a then unpublished version. I am grateful the referee who brought this point to my attention. 